\title{
Keefektifan Model Pembelajaran Novick Terhadap Pemahaman Konsep Fisika Siswa SMK Negeri 17 Samarinda Materi Elastisitas dan Hukum Hooke
}

\author{
Nira Arisa ${ }^{1 *}$, Johansyah ${ }^{2}$, dan M. Khairul Ali Hanif ${ }^{3}$ \\ 1,2,3 Program Studi Pendidikan Fisika Fakultas Keguruan dan IImu Pendidikan \\ Universitas Mulawarman, Samarinda-Indonesia \\ `E-mail : arisa_nira@yahoo.com
}

\begin{abstract}
Abstrak
Penelitian ini bertujuan untuk mengetahui peningkatan pemahaman konsep fisika siswa SMK serta keefektifan model pembelajaran Novick terhadap pemahaman konsep fisika. Populasi pada penelitian ini seluruh siswa kelas X SMKN 17 Samarinda. Teknik pengambilan sampel adalah purposive sampling. Sampel dalam penelitian ini yaitu siswa kelas X-1 dan X-2 Farmasi yang masing-masing berjumlah 35 siswa. Penelitian ini merupakan penelitian kuantitatif dengan desain static-group pre-test post-test design. Instrumen penelitian menggunakan teknik tes berupa soal uraian. Hasil rata-rata pemahaman konsep fisika siswa pada kelas eksperimen mengalami peningkatan dengan $\mathrm{N}$-Gain sebesar 0,68 dengan kategori sedang dan pada kelas kontrol sebesar 0,49 dengan kategori sedang. Peningkatan tertinggi terdapat pada indikator mencontohkan dengan memperoleh hasil $N$-Gain sebesar 0,88 kategori tinggi. Sedangkan peningkatan terendah terdapat pada indikator membandingkan dengan memperoleh hasil $N$-Gain sebesar 0,59 dengan kategori sedang. Penerapan mode pembelajaran Novick untuk meningkatkan pemahaman konsep fisika siswa memiliki tingkat efektifitas yang tinggi dengan effect size sebesar 1,36.
\end{abstract}

Kata kunci: Model Pembelajaran Novick,Pemahaman Konsep, Fisika

\begin{abstract}
The purpose of this research was to find out the intreasement and effectiveness of students' physics concepts understanding in elasticity and hooke's law theory by applying Novick learning model. The population of this research were the tenth grade of students at SMK Negeri 17 Samarinda. The sampling technique used was purposive sampling. The sample of this research were the PHARMACY students X-1 and X-2 PHARMACY classes that consists of 35 people in each class. The research model was a quantitative which is a static-group pre-test and post-test design. The average physics concept understanding in experimental class have increased with the medium category, obstaining $N$-Gain of 0,68 . Where as in the control class there was an increase with a medium category, obtaining $\mathrm{N}$-Gain of 0,49 . The highest increase was in the exemplifies indicator by obtaining an $\mathrm{N}$-Gain of 0,88 in the high category. While the lowest increase is found in the comparing indicator by obstaining an N-Gain of 0,59 in the medium category. The Novick learning model to improve students' physics concepts understanding has a high level of effectiveness, showed by the calculation of the effect size on 1,36.
\end{abstract}

Keywords: Novick Learning Model, Pysick Concept Understanding

Article History: Received: 6 Januari 2020

Accepted: 9 Januari 2020

Revised : 20 Januari 2020

Published: 31 Januari 2020

How to cite: Arisa, N., Johansyah, dan Hanif, M.K.A.(2020). Keefektifan Model Pembelajaran Novick Terhadap Pemahaman Konsep Fisika Siswa SMK Negeri 17 Samarinda Materi Elastisitas Dan Hukum Hooke, 1(1). pp.45-55. Retrieved from http://jurnal.fkip.unmul.ac.id/index.php/jpfp/index

Copyright (C) Januari 2020, Jurnal Literasi Pendidikan Fisika 


\section{PENDAHULUAN}

Pendidikan memiliki peranan yang sangat penting dalam kehidupan manusia, karena pendidikan dapat mempengaruhi perkembangan manusia dalam seluruh aspek kepribadian dan kehidupannya. Pendidikan dapat mengembangkan berbagai potensi yang dimiliki manusia secara optimal, yaitu pengembangan potensi individu yang setinggitingginya dalam aspek fisik, intelektual, emosional, sosial, dan spiritual sesuai dengan tahap perkembangan serta karakteristik lingkungan fisik dan lingkungan sosial budaya dimana dia hidup (Taufiq, Mikarsa, \& Prianto, 2010). Selain itu pendidikan juga memegang peran yang sangat penting dalam peningkatan kualitas sumber daya manusia (SDM). Pendidikan dalam prakteknya berkaitan erat dengan belajar yaitu kegiatan yang berproses dan merupakan unsur yang sangat mendasar dalam setiap penyelenggaraan jenis dan jenjang pendidikan. Ini berarti berhasil atau tidaknya pencapaian tujuan pendidikan itu sangat bergantung pada proses belajar yang dialami siswa.

Pemahaman memerlukan kemampuan menangkap makna dan arti dari suatu konsep (Sudjana, 2016). Pemahaman konsep menjadi dasar seseorang untuk memahami permasalahan fisika dan membuat hubunganhubungan antar konsep dalam penyelesaian masalah (Trianggono, 2017).

Dalam kegiatan belajar mengajar fisika, pemahaman konsep dalam diri siswa penting untuk ditingkatkan agar siswa dapat lebih mememahami konsep fisika sehingga apabila dihadapkan dengan permasalahan atau soal fisika siswa dengan mudah dapat memecahkan permasalahan atau soal tersebut. Siswa tidak hanya menghafal rumus dasar dari materi saja, tetapi lebih memahami konsep dasar fisika yang dimiliki siswa sehingga siswa tidak lagi merasa terbebani dengan soal fisika.

Guru merupakan faktor penting dalam proses pembelajaran, karena guru berhadapan langsung dengan peserta didik dalam proses pembelajaran, melalui guru pula ilmu pengetahuan dapat ditransfer kepada peserta didik. Guru memiliki tanggung jawab besar yang mau tidak mau harus dilaksanakannya sebagai guru. Guru harus bertanggung jawab atas hasil kegiatan belajar siswa melalui interaksi selama proses pembelajaran berlangsung.

Guru merupakan faktor yang mempengaruhi berhasil atau tidaknya proses pembelajaran, dan guru juga harus dapat menguasai prinsipprinsip terhadap proses belajar mengajar. Dengan kata lain guru harus mampu menciptakan situasi kondisi belajar sebaikbaiknya dengan cara menggunakan model pembelajaran yang bervariasi dan disesuaikan dengan karakteristik konsep yang akan diajarkan untuk pembelajaran yang lebih efektif. Sebab pada semua bidang pendidikan formal maupun bidang studi harus dapat memanfaatkan mental pada tiap anak agar kemampuan mental kearah kematangan dan kedewasaan dalam arti luas secara terarah dan teratur dapat meningkat.

Berdasarkan hasil wawancara peneliti dengan guru mata pelajaran fisika di SMK Negeri 17 Samarinda yang mengampu kelas $X$ dan XII sebagai observasi awal ditemukan beberapa kendala bahwa siswa pada umumnya berpandangan fisika merupakan pelajaran yang sulit dan memiliki persamaan yang rumit. Hal ini nampak dari hasil ulangan harian, selain itu, dari hasil wawancara dari beberapa siswa kelas $X$ SMK Negeri 17 Samarinda ditemukan beberapa informasi bahwa pada proses pembelajaran fisika berpusat pada guru (teacher center). Dalam hal ini siswa tidak berperan besar dalam proses pembelajaran yang berpusat pada guru yang mengakibatkan siswa pasif dan motivasi untuk belajar rendah.

Selain itu guru sering memberi latihan soal setelah menjelaskan materi, akan tetapi pada saat proses pembelajaran berlangsung tidak terlalu menguatkan konsep siswa, sehingga ketika mengerjakan soal siswa banyak melakukan kesalahan, padahal ketika proses pembelajaran siswa banyak yang sudah paham dengan materi yang diajarkan. Sebagian besar siswa menghafal rumus yang diberikan oleh guru, tanpa memahami bagaimana proses rumus tersebut terbentuk. Berdasarkan masalah tersebut, peneliti dapat mengetahui bahwa pemahaman konsep fisika pada peserta didik di sekolah tersebut masih kurang.

Seharusnya dalam kegiatan pembelajaran siswa tidak hanya menerima pengetahuan tetapi siswa harus mampu mengaplikasikan pengetahuan yang dimilikinya dalam kehidupan 
sehari-hari, dan untuk mengaplikasikan pengetahuan yang dimilikinya, siswa harus terlebih dahulu memahami apa yang dipelajarinya. Proses yang harus dilakukan siswa sebelum memahami yaitu mengenal terlebih dahulu materi tersebut. Model pembelajaran yang digunakan kurang tepat dan kurang variatif sehingga pembelajaran menjadi kurang bermakna dan peran guru yang terlalu dominan bahkan cenderung hanya bersikap pasif saja pada saat proses pembelajaran berlangsung.

Berlatar belakang dari permasalahan yang terjadi di atas, dibutuhkan suatu proses pembelajaran yang baik untuk pembelajaran fisika. Peneliti mencoba untuk merancang penelitian dengan menggunakan model pembelajaran yang menduga siswa dapat lebih aktif yaitu model pembelajaran Novick. Model pembelajaran Novick adalah suatu model pembelajaran yang berawal dari konsep belajar, sebagai perubahan konseptual yang dikembangkan dari pendekatan konstruktivisme. Rezeki (2017), menyatakan bahwa model pembelajaran Novick ini dikemukakan oleh Nussbaum dan Novick terdiri dari 3 fase, yaitu: fase pertama, mempertunjukkan kerangka kerja alternative siswa (exposing alternative frameworks) pada fase ini siswa diharapkan mengungkapkan konsepsi awal peserta didik agar guru mengenali pemahaman gagasan atau konsepsi awal siswa. Fase kedua, menciptakan konflik konseptual (creating conceptual conflict), pada fase konflik kognitif memicu siswa untuk lebih tertantang untuk belajar, pada fase ini siswa lebih tertantang dalam struktur kognitif peserta didik yang mereka ketahui sebelumnya dan fakta apa yang siswa lihat pada kehidupan sehari hari belum cocok dengan skema yang telah ada. Fase ketiga mendorong terjadinya akomodasi kognitif (encouraging cognitive accomodation). Pada fase ini akomodasi kognitif bertujuan untuk membentuk skema baru yang cocok dengan ransangan yang baru atau modifikasi skema yang ada sehingga sesuai dengan konsep yang ilmiah. Keunggulan model pembelajaran Novick adalah proses penyimpanan memori pengetahuan yang diperoleh siswa berlangsung lebih lama dan dapat mengembangkan kemampuan berpikir siswa menjadi berpikir ilmiah (Andriani, Antari, \& Rati, 2014). Selain itu, penerapan model pembelajaran ini juga menjadikan siswa aktif dalam proses pembelajaran sehingga siswa lebih termotivasi dalam belajar (Sulaiman, 2012).

Berdasarkan penjelasan di atas maka dapat dikatakan bahwa model pembelajaran Novick diyakini akan mampu meningkatkan pemahaman konsep fisika, hal ini diperkuat dengan penelitian yang telah dilakukan oleh Kalsum (2017). Hasil penelitian menunjukkan bahwa skor rata-rata pretest sebesar 3,2 dan skor rata-rata posttest sebesar 7,8. Dalam hal ini pemahaman konsep fisika siswa sebelum diajar menggunakan model pembelajaran Novick berada pada kategori rendah sedangkan pemahaman konsep fisika siswa setelah diajar menggunakan model pembelajaran Novick berada pada kategori sedang. Berdasarkan analisis inferensial diperoleh $\mathrm{t}$ hitung $=8,529>\mathrm{t}$ tabel $=2,093$, maka $\mathrm{Ha}$ diterima. Dengan demikian dapat diketahui bahwa terdapat perbedaan yang signifikan terhadap pemahaman konsep fisika siswa kelas XI MIPA SMA Negeri 1 Pamboang sebelum dan setelah diterapkan model pembelajaran Novick.

Menurut Kalsum (2017), dapat diyakini bahwa dengan model pembelajaran Novick akan memicu kreatifitas dan potensi kritis siswa untuk aktif dalam proses pembelajaran. Dengan pembelajaran yang demikian, siswa akan mendapatkan pembelajaran yang bermakna dan menyenangkan, sehingga mereka terlepas dari perasaan bosan dan beban untuk mempelajari sekian banyak materi dan rumus dalam fisika seperti yang sering dihadapi siswa jika pembelajaran yang disampaikan

\section{METODE}

Penelitian ini merupakan penelitian kuantitatif. Metode penelitian yang digunakan dalam penelitian adalah Pretest-Posttest Group Control Design. Penelitian dilaksanakan pada bulan Juli-September 2019 di SMK Negeri 17 Samarinda pada kelas $X$. Teknik pengumpulan data yang digunakan adalah teknik tes untuk mengukur kemampuan pemahaman konsep fisika. Tes ini berupa lembar evaluasi pretest dan posttest untuk mengetahui tingkat kemampuan pemahaman konsep fisika siswa, yaitu pretest yang dilakukan pada awal 
Keefektifan Model Pembelajaran...

pembelajaran dan posttest yang dilakukan pada akhir pembelajaran pokok bahasan elastisitas dan hukum hooke.

Pada penelitian ini, aspek yang dinilai adalah peningkatan pemahaman konsep fisika yang dihitung dengan Analisis $\mathrm{N}$-Gain pemahaman konsep fisika.

Untuk menganalisis penilaian data pemahaman konsep fisika siswa, digunakan rumus:

Nilai $=\frac{\sum \text { prolehan skor }}{\sum \text { skor maksimum }} \times 100$

Kemudian digunakan mean untuk mengetahui nilai rata-rata siswa setelah mengikuti pretest dan posttest. Rumus mean yang digunakan sebagai berikut:

$\bar{x}=\frac{\sum x}{n}$

Peningkatan kemampuan pemahaman konsep fisika dengan menggunakan $\mathrm{N}$-Gain. Rumus N-Gain menurut Hake (2002), yaitu:

$N$-Gain $=\frac{\text { skor posttest }- \text { skor } \text { pretest }}{(\text { skor ideal }- \text { skor pretest })}$

Pengaruh model pembelajaran Novick terhadap pemahaman konsep fisika siswa dihitung menggunakan uji non parametrik yaitu uji Mann Witney $U$ test. Karena data yang diperoleh tidak normal dan tidak homogen. Uji tersebut digunakan untuk mengambil keputusan apakah hipotesis penelitian diterima atau ditolak.

Effect Size pada penelitian digunakan untuk mengetahui efektivitas model pembelajaran Novick, terhadap peningkatan pemahaman konsep fisika. Effect Size dapat dihitung dengan formulasi Cohen yaitu :

$d=\frac{m_{A}-m_{B}}{\left\{\frac{\left(s d_{A}^{2}+s d_{B}^{2}\right)}{2}\right\}^{\frac{1}{2}}}$

\section{HASIL DAN PEMAHASAN}

HASIL

Hasil rata-rata pretest dan posttest kelas eksperimen dan kelas kontrol sebelum dan sudah diterapkan model pembelajaran Novick. Hasil rata-rata pretest dan posttest kelas eksperimen dan kontrol dapat dilihat pada tabel 1.
Tabel 1. Hasil Rata-rata Pretest dan Posttest Kelas eksperimen dan kontrol

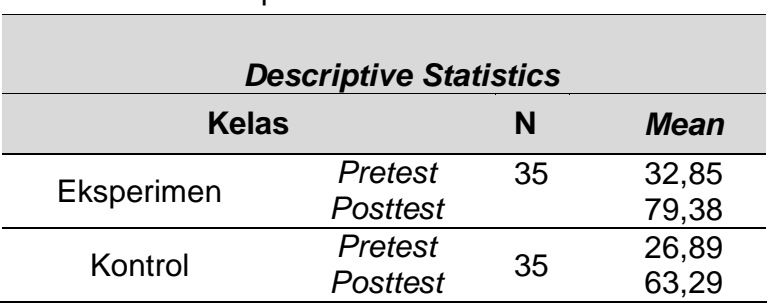

Peningkatan pemahaman konsep fisika siswa dengan menerapkan model pembelajaran Novick pada kelas eksperimen dapat dilihat pada tabel 2 .

Tabel 2. Analisis N-Gain

\begin{tabular}{ccccc}
\hline \multirow{2}{*}{ Kelas } & $\begin{array}{c}\text { Pre- } \\
\text { test }\end{array}$ & $\begin{array}{c}\text { Post- } \\
\text { test }\end{array}$ & $\begin{array}{c}\text { N- } \\
\text { Gain }\end{array}$ & \multirow{2}{*}{ Ket } \\
\cline { 2 - 4 } Mean & Mean & Mean & \\
\hline \multirow{2}{*}{ Eksperimen } & 32,97 & 79,26 & 0,68 & Sedang \\
\hline \multirow{2}{*}{ Kontrol } & 26,86 & 63,29 & 0,49 & Sedang
\end{tabular}

Kategori peningkatan pemahaman konsep fisika siswa setiap indikator setelah menerapkan model pembelajaran Novick dapat dilihat pada tabel 3 .

Tabel 3. Kategori Perolehan Nilai N-Gain Setiap Indikator

Eksperimen

\begin{tabular}{lcc} 
& \multicolumn{2}{c}{ Eksperimen } \\
\cline { 2 - 3 } \multicolumn{1}{c}{ Indikator } & N-Gain & Kategori \\
& & \\
\hline Classifying & 0,6 & Sedang \\
\hline Exemplifying & 0,88 & Tinggi \\
\hline Interpreting & 0,71 & Tinggi \\
\hline Inferring & 0,73 & Tinggi \\
\hline Comparing & 0,59 & Sedang \\
\hline
\end{tabular}

Kategori peningkatan pemahaman konsep fisika siswa setiap indikator setelah menerapkan model pembelajaran Novick pada kelas kontrol dapat dilihat pada tabel 4 .

Tabel 4. Kategori Peningkatan Pemahaman Konsep Fisika Siswa Setiap Indikator

\begin{tabular}{lcc} 
& \multicolumn{2}{c}{ Kontrol } \\
\cline { 2 - 3 } Indikator & $\mathrm{N}$-Gain & Kategori \\
& & \\
\hline Classifying & 0,72 & Tinggi \\
\hline
\end{tabular}


Keefektifan Model Pembelajaran...

\begin{tabular}{lll}
\hline \multirow{2}{*}{ Indikator } & \multicolumn{2}{c}{ Kontrol } \\
\cline { 2 - 3 } & $\mathrm{N}$-Gain & Kategori \\
\hline Exemplifying & 0,91 & Tinggi \\
\hline Interpreting & 0,52 & Sedang \\
\hline Inferring & 0,32 & Sedang \\
\hline Comparing & 0,17 & Rendah \\
\hline
\end{tabular}

Hasil uji normalitas data pretest kelas eksperimen dan kelas kontrol menggunakan metode Shapiro Wilk dengan bantuan software SPSS 23.0 for Windows dapat dilihat pada tabel 5.

Tabel 5. Hasil Uji Normalitas Data Pretest Kelas Eksperimen dan Kelas Kontrol

\begin{tabular}{lllll}
\hline \multicolumn{5}{c}{$\begin{array}{c}\text { Test Of Normality } \\
\text { Shapiro-Wilk }\end{array}$} \\
\hline Kelompok & Statistic & Df & Sig. \\
\hline Pre-test & $\begin{array}{l}\text { Kelas } \\
\text { Eksperimen }\end{array}$ & 0,96 & 35 & 0,42 \\
\hline & $\begin{array}{l}\text { Kelas } \\
\text { Kontrol }\end{array}$ & 0,93 & 35 & 0,94 \\
\hline
\end{tabular}

Hasil uji homogenitas data pretest kelas eksperimen dan kelas kontrol menggunakan uji levene dengan bantuan software SPSS 23.0 for Windows dapat dilihat pada tabel 6.

Tabel 6. Hasil Uji Homogenitas Data Pretest Kelas Ekseprimen dan Kelas Kontrol

\begin{tabular}{ccc}
\hline \multicolumn{3}{c}{ Test of Homogeneity of Variance } \\
\hline & & Sig. \\
\hline \multirow{3}{*}{ Pretest } & Based on Mean & .176 \\
& Based on Median & .223 \\
& Based on Median and with & .224 \\
\hline
\end{tabular}

Hasil Uji t Independen data pretest kelas eksperimen dan kelas kontrol dilakukan untuk mengetahui ada tidaknya perbedaan pretest kelas eksperimen dan kelas kontrol dengan bantuan software SPSS 23.0 for Windows dapat dilihat pada tabel 7 .

Tabel 7. Hasil Uji t Independen Data Pretest Kelas

\begin{tabular}{ccc}
\multicolumn{3}{c}{ Ekseprimen dan Kelas Kontrol } \\
\hline \multicolumn{3}{c}{$\begin{array}{l}\text { Independent Samples Test } \\
\text { t-test for Equality of Means }\end{array}$} \\
\hline & $\boldsymbol{T}$ & Sig. (2-tailed) \\
\hline $\begin{array}{c}\text { Equal variances } \\
\text { assumed }\end{array}$ & 2,516 & 0,014 \\
\hline
\end{tabular}

\begin{tabular}{|ccc|}
\hline \multicolumn{3}{|c|}{$\begin{array}{l}\text { Independent Samples Test } \\
\text { t-test for Equality of Means }\end{array}$} \\
\hline & $\boldsymbol{T}$ & Sig. (2-tailed) \\
\hline $\begin{array}{c}\text { Equal variances not } \\
\text { assumed }\end{array}$ & 2,516 & 0,014 \\
\hline
\end{tabular}

Hasil uji homogenitas data $\mathrm{N}$-Gain kelas eksperimen dan kelas kontrol menggunakan uji levene dengan bantuan software SPSS 23.0 for Windows dapat dilihat pada tabel 9.

Tabel 9. Hasil Uji Homogenitas Data N-Gain Kelas Ekseprimen dan Kelas Kontrol

\begin{tabular}{ccc}
\hline \multicolumn{3}{c}{ Test of Homogeneity of Variance } \\
\hline \multirow{4}{*}{ NGain } & \multicolumn{2}{c}{ Sig. } \\
\hline \multirow{3}{*}{\begin{tabular}{cc} 
Based on Mean \\
\cline { 2 - 3 }
\end{tabular}} & .000 \\
\cline { 2 - 3 } & $\begin{array}{c}\text { Based on Median } \\
\text { with adjusted df }\end{array}$ & .000 \\
\cline { 2 - 3 } & $\begin{array}{c}\text { Based on trimmed } \\
\text { mean }\end{array}$ & .000 \\
\hline
\end{tabular}

Hasil Uji Mann Whitney U Test data N-Gain kelas eksperimen dan kelas kontrol dilakukan untuk mengetahui ada tidaknya perbedaan pretest kelas eksperimen dan kelas kontrol dengan bantuan software SPSS 23.0 for Windows dapat dilihat pada tabel 10.

Tabel 10. Hasil Uji Mann Whitney U Test

\begin{tabular}{lr}
\hline \multicolumn{2}{c}{ Test Statistics $^{a^{2}}$} \\
\hline & \multicolumn{1}{c}{ NGain } \\
\hline Mann-Whitney U & 195.500 \\
\hline Wilcoxon W & 825.500 \\
\hline$Z$ & -4.900 \\
\hline Asymp. Sig. (2-tailed) & .000 \\
\hline
\end{tabular}

Hasil uji normalitas data $\mathrm{N}$-Gain tiap indikator pemahaman konsep fiisika kelas eksperimen dengan bantuan software SPSS 23.0 for Windows dapat dilihat pada tabel 11.

Tabel 11. Hasil Uji Normalitas Data N-Gain Tiap Indikator Pemahaman Konsep Fisika Kelas Eksperimen

\begin{tabular}{|c|c|c|}
\hline \multirow{2}{*}{$\begin{array}{l}\text { Indikator } \\
\text { Pemahaman } \\
\text { Konsep }\end{array}$} & \multicolumn{2}{|c|}{ Uji Normalitas } \\
\hline & Eksperimen & SD \\
\hline \multirow{2}{*}{ Classifying } & Tidak Normal & \multirow{2}{*}{0,51} \\
\hline & $($ Sig. 0,00) & \\
\hline \multirow{2}{*}{ Exemplifying } & Tidak Normal & \multirow{2}{*}{0,29} \\
\hline & $($ Sig. 0,00) & \\
\hline \multirow{2}{*}{ Interpreting } & Normal & \multirow{2}{*}{0,13} \\
\hline & $($ Sig. 0,16) & \\
\hline \multirow{2}{*}{ Inferring } & Tidak Normal & \multirow{2}{*}{0,31} \\
\hline & $($ Sig. 0,00) & \\
\hline
\end{tabular}


Keefektifan Model Pembelajaran...

\begin{tabular}{ccc}
\hline \multirow{2}{*}{$\begin{array}{c}\text { Indikator } \\
\text { Pemahaman } \\
\text { Konsep }\end{array}$} & \multicolumn{2}{c}{ Uji Normalitas } \\
\cline { 2 - 2 } & Eksperimen & SD \\
\hline Comparing & Tidak Normal & 0,19 \\
\cline { 2 - 2 } & (Sig. 0,02) & \\
\hline
\end{tabular}

Hasil uji normalitas data $\mathrm{N}$-Gain tiap indikator pemahaman konsep fiisika kelas kontrol dengan bantuan software SPSS 23.0 for Windows dapat dilihat pada tabel 12.

Tabel 12. Hasil Uji Normalitas Data N-Gain Tiap Indikator Pemahaman Konsep Fisika Kelas Kontrol

\begin{tabular}{|c|c|c|}
\hline \multirow{2}{*}{$\begin{array}{c}\text { Indikator } \\
\text { Pemahaman } \\
\text { Konsep }\end{array}$} & \multicolumn{2}{|c|}{ Uji Normalitas } \\
\hline & Kontrol & SD \\
\hline \multirow{2}{*}{ Classifying } & Tidak Normal & \multirow{2}{*}{0,39} \\
\hline & $($ Sig. 0,00) & \\
\hline \multirow{2}{*}{ Exemplifying } & Tidak Normal & \multirow{2}{*}{0,22} \\
\hline & (Sig. 0,00) & \\
\hline \multirow{2}{*}{ Interpreting } & Normal & \multirow{2}{*}{0,18} \\
\hline & (Sig. 0,13) & \\
\hline \multirow{2}{*}{ Inferring } & Tidak Normal & \multirow{2}{*}{0,73} \\
\hline & (Sig. 0,00) & \\
\hline \multirow{2}{*}{ Comparing } & Tidak Normal & \multirow{2}{*}{0,39} \\
\hline & (Sig. 0,05) & \\
\hline
\end{tabular}

Hasil uji perbedaan rata-rata $\mathrm{N}$-Gain tiap indikator pemahaman konsep fiisika kelas eksperimen dan kelas kontrol dengan bantuan software SPSS 23.0 for Windows dapat dilihat pada tabel 13.

Tabel 13. Hasil Uji Perbedaan Rata-rata N-Gain Tiap Indikator Pemahaman Konsep Fisika

\begin{tabular}{ccc}
\hline $\begin{array}{c}\text { Indikator } \\
\text { Pemahaman } \\
\text { Konsep }\end{array}$ & \multicolumn{2}{c}{ Uji Beda } \\
\cline { 2 - 3 } Classifying & Rata-rata & Makna \\
\cline { 2 - 3 } & $\mathrm{Z}=-727$ & Berbeda \\
\hline \multirow{2}{*}{ Exemplifying } & Sig. 0,47$)$ & Signifikan \\
\cline { 2 - 3 } & $\mathrm{Z}=-644$ & Tidak Berbeda \\
\hline \multirow{2}{*}{ Interpreting } & Sig. 0,52) & Signifikan \\
\cline { 2 - 3 } & $\mathrm{T}=4,606$ & Berbeda \\
\hline \multirow{2}{*}{ Inferring } & (Sig. 0,00$)$ & Signifikan \\
\cline { 2 - 3 } & $\mathrm{Z}=-3,06$ & Berbeda \\
\hline \multirow{2}{*}{ Comparing } & $($ Sig. 0,00$)$ & Signifikan \\
\cline { 2 - 3 } & $\mathrm{Z}=-4,145$ & Berbeda \\
\hline
\end{tabular}

Hasil uji effect size kelas eksperimen dan kelas kontrol dilakukan untuk mengetahui efektivitas model pembelajaran Novick terhadap pemahaman konsep fisika siswa dapat dilihat pada tabel 14 .

Tabel 14. Uji Effect Size

\begin{tabular}{cccc}
\hline Kelas & N-Gain & $\begin{array}{c}\text { Effect } \\
\text { Size }(\boldsymbol{d})\end{array}$ & Kategori \\
\cline { 1 - 2 } Eksperimen & 0,68 & \multirow{2}{*}{1,36} & Tinggi \\
\hline Kontrol & 0,49 & & \\
\hline
\end{tabular}

Hasil uji effect size kelas eksperimen untuk setiap indikator pemahaman konsep fisika dilakukan untuk mengetahui efektivitas model pembelajaran Novick terhadap pemahaman konsep fisika siswa dapat dilihat pada tabel 15.

Tabel 15. Hasil Uji Effect Size Tiap Indikator Pemahaman Konsep Fisika

\begin{tabular}{|c|c|c|c|c|}
\hline \multirow{2}{*}{ Indikator } & Eks. & Kontrol & \multirow{2}{*}{$\begin{array}{c}\text { Effect } \\
\text { Size }\end{array}$} & \multirow{2}{*}{ Kategor } \\
\hline & $N$-Gain & N-Gain & & \\
\hline Classifying & 0,6 & 0,72 & $-0,31$ & $\begin{array}{c}\text { Tidak } \\
\text { Efektif }\end{array}$ \\
\hline Exemplifying & 0,88 & 0,91 & $-0,12$ & $\begin{array}{l}\text { Tidak } \\
\text { Efektif }\end{array}$ \\
\hline Interpreting & 0,71 & 0,52 & 0,36 & Sedang \\
\hline Inferring & 0,73 & 0,32 & 0,73 & Tinggi \\
\hline Comparing & 0,59 & 0,17 & 2,33 & Tinggi \\
\hline
\end{tabular}

\section{PEMBAHASAN}

Berdasarkan Tabel 1 diperoleh rata-rata pretest kelas eksperimen adalah 32,85 sedangkan rata-rata pretest kelas kontrol adalah 26,89. Hal ini menunjukkan bahwa pemahaman konsep fisika awal siswa sebelum diberikan pembelajaran dengan menggunakan model yang berbeda antara kelas eksperimen dan kelas kontrol relatif rendah yang di ukur mengunakan pretest, Namun setelah diberikan pembelajaran dengan menggunakan model yang berbeda antara kelas eksperimen dan kelas kontrol, maka terdapat perbedaan dan peningkatan terhadap pemahaman konsep fisika siswa. Dalam hal ini penulis mengukurnya dengan posttest. Selanjutnya dapat diketahui bahwa rata-rata posttest kelas eksperimen adalah 79,26 sedangkan rata-rata posttest kelas kontrol adalah 63,29. Berdasarkan hasil nilai posttest tersebut dapat disimpulkan bahwa nilai posttest pemahaman konsep fisika siswa materi elastisitas dan hukum hooke di kelas X-1 Farmasi memberikan hasil yang lebih tinggi dibandingkan dengan nilai posttest siswa kelas X-2 Farmasi SMK Negeri 17 Samarinda yang 
Keefektifan Model Pembelajaran...

diajar menggunakan model pembelajaran konvensional. Penelitian ini sejalan dengan penelitian yang telah dilakukan oleh Marlina (2014), yang memberikan hasil yaitu menunjukkan bahwa pemahaman konsep siswa yang diajar dengan model pembelajarn Novick lebih tinggi daripada siswa yang diajar dengan model pembelajaran konvensional. Penelitian yang dilakukan Stanvinibilla (2016), memberikan hasil yaitu terdapat pengaruh model pembelajarn Novick terhadap hasil belajar siswa.

Berdasarkan tabel 2 analisis $\mathrm{N}$-Gain diperoleh $\mathrm{N}$-Gain kelas eksperimen sebesar 0,68 dengan kriteria sedang. Sedangkan pada kelas kontrol diperoleh $\mathrm{N}$-Gain sebasar 0,49 dengan kriteria sedang. Hal ini menunjukkan bahwa penerapan model pembelajaran Novick dan konvensional dapat meningkatkan pemahaman konsep fisika siswa, namun berdasarkan hasil $\mathrm{N}$-Gain secara keseluruhan model pembelajaran Novick cukup baik diterapkan dibandingkan dengan model konvensional. Pada kelas kontrol, pemahaman konsep fisika siswa lebih rendah daripada kelas eksperimen. Hal ini disebabkan karena siswa cenderung untuk aktif hanya pada penyelesaian masalah berupa soal-soal hitungan. Melalui model pembelajaran konvensional yang diterapkan pada kelas kontrol, siswa kurang memilki kesempatan untuk mengasah pemahaman berfikirnya untuk memecahkan suatu permasalahan yang lebih kompleks. Siswa tidak melakukan praktikum pada kelas kontrol, sehingga pemahaman menghasilkan berbagai macam kemungkinan jawaban kurang terbentuk. Selain itu juga terdapat beberapa siswa menjadi kurang aktif karena tertinggal dengan siswa lainnya yang lebih cepat paham, beberapa siswa yang kurang aktif tersebut hanya menyalin jawaban dari contoh-contoh soal yang telah diselesaikan oleh siswa yang lain. Penelitian ini sejalan dengan penelitian yang telah dilakukan oleh Ardi (2016), yang memberikan hasil yaitu model pembelajaran Novick leih efektif dalam meremediasi miskonsepsi peserta didik, sehingga diharapkan bisa menjadi salah satu alternatif model pembelajaran dalam pembelajaran fisika.

Berdasarkan tabel 3 dan tabel 4 kategori perolehan nilai $\mathrm{N}$-Gain setiap indikator pemahaman konsep fisika pada kelas eksperimen dan kelas kontrol, menunjukkan bahwa pada indikator classifying pada kelas eksperimen memperoleh hasil 0,60 kriteria sedang, dan pada kelas kontrol memperoleh hasil 0,72 kriteria tinggi. Hasil tersebut menunjukkan bahwa kelas kontrol memperoleh $\mathrm{N}$-Gain yang lebih tinggi dari kelas ekseperimen. Hal ini menunjukkan bahwa model pembelajaran Novick masih kurang diterapkan pada berfikir siswa dalam mengklasifikasikan. Melalui model pembelajaran Novick siswa lebih dituntut untuk dapat mengklasifikasikan atau membedakan suatu objek dalam permasalahan yang diberikan.

Indikator exemplifying pada kelas eksperimen memperoleh hasil 0,88 kriteria tinggi, dan pada kelas kontrol memperoleh hasil 0,91 kriteria tinggi. Artinya hasil tersebut menunjukkan bahwa antara kelas eksperimen dan kelas kontrol sama-sama memperoleh $\mathrm{N}$ Gain pada kategori tinggi. Hal ini menandakan bahwa perbedaan peningkatan indikator exemplifying (mencontohkan) antara dua kelas sangat sedikit bahkan hampir tidak ada perbedaan. Melalui model pembelajaran Novick, siswa dilatih untuk lebih mudah mengungkapkan ide dan memberikan contoh serta memperdalam gagasannya untuk memberikan ide dan memberi contoh dari permalsahan yang diberikan. Pada model konvensional, indikator mencontohkan memang juga dikembangkan namun melalui latihan soal-soal tanpamenitikberatkan pada pemahaman konsep melalui masalah seperti yang dilakukan pada model pembelajaran Novick. Sehingga peningkatan indikator mencontohkan antara dua kelas dikategorikan sama.

Indikator interpretation pada kelas eksperimen memperoleh hasil 0,71 kriteria tinggi, dan pada kelas kontrol memperoleh hasil 0,52 kriteria sedang. Artinya hasil tersebut menunjukkan bahwa $\mathrm{N}$-Gain kelas eksperimen lebih tinggi dari kelas kontrol. Melalui model pembelajaran Novick menunjukkan bahwa, siswa dilatih untuk menginterpretasi atau terlatih dalam mengubah bentuk dari satu 
bentuk kebentuk yang lain pada permasalahan yang di sajikan. Sedangkan model konvensional, berfikir siswa kurang dilatih dalam menginterpretasi permasalahan yang diberikan.

Indikator inferring pada kelas eksperimen memperoleh hasil 0,73 kriteria tinggi, dan pada kelas kontrol memperoleh hasil 0,32 kriteria sedang. Artinya hasil tersebut menunjukkan bahwa $\mathrm{N}$-Gain kelas eksperimen lebih tinggi dari kelas kontrol. Hal ini menunjukkan model pembelajaran Novick lebih baik diterapkan tehadap berfikir siswa dalam indikator menyimpulkan. Melalui model pembelajaran Novick, siswa dilatih dalam proses pembelajaran yang diterapkan untuk menyimpulkan dari permasalahan yang disajikan. Sedangkan model konvensional, siswa hanya terfokus untuk menyelesaikan soal-soal yang diberikan tanpa harus menganalisis dan menyimpulkan soal tersebut.

Indikator comparing pada kelas eksperimen memperoleh hasil 0,59 kriteria sedang, dan pada kelas kontrol memperoleh hasil 0,17 kriteria rendah. Artinya hasil tersebut menunjukkan bahwa kelas eksperimen memperoleh $\mathrm{N}$-Gain yang lebih tinggi dari kelas kontrol. Melalui model pembelajaran Novick, cara berfikir siswa di tuntut dapat untuk dapat membendingkan atau mencari hubungan antara dua ide, objek, dan hal yang sama yang disajikan dalam bentuk soal yang menjadi titik permasalhan. Pada model konvensional, siswa hanya diberikan soal-soal latihan saja tanpa dituntut dalam membandingkan atau mencari hubungan antara dua ide. Hal ini menujukkan bahwa nilai $\mathrm{N}$-Gain setiap indikator, menujukkan hasil yang bervariasi.

Menafsirkan uji Shapiro-Wilk dan uji levene dilakukan dengan melihat bilangan yang terdapat dalam kolom signifikan (Sig.). Data dikatakan terdistribusi normal apabila nilai signifikansi lebih besar dari 0,05 dan data dikatakan tidak terdistribusi normal apabila nilai signifikansi kurang dari 0,05. Berdasarkan tabel 5 hasil uji normalitas data pretest kelas eksperimen dan kelas kontrol menggunakan metode Shapiro-Wilk diperoleh nilai signifikansi pada kelas eksperimen adalah 0,42 dan kelas kontrol adalah 0,94 dimana nilai tersebut lebih dari 0,05 , sehingga dapat disimpulkan bahwa data pretest terdistribusi normal, karena data terdistribusi normal dilanjutkan dengan uji homogenitas menggunakan levene, yang dapat dilihat pada tabel 6 diperoleh nilai signifikasi lebih besar dari 0,05 , sehingga dapat disimpulkan bahwa data pretest pada kelas eksperimen dan kelas kontrol mempunyai nilai varian yang sama (homogen). Maka untuk mengetahui pengaruhnya digunakan uji $t$ independen. Hasil dari uji $t$ independen, dapat dilihat pada tabel 7 nilai signifikan adalah 0,014 kurang dari 0,050 maka dapat disimpulkan ada perbedaan yang signifikan terhadap pemahaman konsep fisika siswa antara dua kelas. Hasil penelitian ini sejalan dengan penelitian yang telah dilakukan oleh Ummu Kalsum (2017), memberikan hasil bahwa pemahaman konsep fisika sebelum diajar menggunakan model pembelajaran Novick berada pada kategori rendah sedangkan pemahaman konsep fisika siswa setelah diajar menggunakan model pembelejaran Novick berada pada kategori sedang. Berdasarkan analisis inferensial thitung $=8,529>$ ttabel $=$ 2,093, maka Ho ditolak dan $\mathrm{Ha}$ diterima. Dengan demikian dapat di ambil kesimpulan bahwa terdapat perbedaan yang signifikan terhadap pemahaman konsep fisika siswa sebelum dan sesudah diterapkan model pembeljaran Novick. Penelitian ini juga sejalan dengan penelitian yang telah dilakukan oleh Ardiansyah \& Ali (2015), memberikan hasil bahwa penerapan model pembelajaran Novick dapat meningkatkan hasil belajar peserta didik kelas X SMA Negeri 1 Sojol. Hal ini terlihat dari pengujian hipotesis dengan perolehan thitung adalah 2,67 . Sedangkan nilai tabel dengan $-t(1-$ $0,5 \alpha)<t<t(1-0,5 \alpha)$, pada taraf nyata $\alpha=0,05$ dan $\mathrm{dk}=\left(\mathrm{n}_{1}+\mathrm{n}_{2}\right)-2=(42+43)-2=83$, diperoleh t $0,95(83)=1,67$. Perolehan tersebut berarti, nilai thitung berada pada daerah penolakan $\mathrm{H}_{\circ}$ dan $\mathrm{H}_{1}$ diterima.

Selanjutnya dilakukan hasil uji beda data $\mathrm{N}$ Gain kelas eksperimen dan kelas kontrol, berdasarkan tabel 8 hasil uji normalitas data $\mathrm{N}$ Gain kelas eksperimen dan kelas kontrol menggunakan metode Shapiro-Wilk diperoleh nilai signifikasi pada kelas eksperimen adalah 0,930 dan kelas kontrol adalah 0,252 dimana 
Keefektifan Model Pembelajaran...

nilai tersebut lebih dari 0,05 , sehingga dapat disimpulkan bahwa data pretest terdistribusi normal, karena data terdistribusi normal, dilanjutkan dengan uji homogenitas menggunakan levene, yang dapat dilihat pada tabel 9 diperoleh nilai signifikasi lebih kecil dari 0,05 , sehingga dapat disimpulkan bahwa data $\mathrm{N}$-Gain pada kelas eksperimen dan kelas kontrol mempunyai nilai varian yang tidak sama (tidak homogen). Maka untuk mengetahui penrbedaannya digunakan uji non- parametrik, yaitu Mann Whitney U Test. Hasil dari Uji Mann Whitney $U$ Test, dapat dilihat pada tabel 10 nilai signifikan adalah 0,000 kurang dari 0,000 maka dapat disimpulkan ada perbedaan yang signifikan terhadap pemahaman konsep fisika siswa antara dua kelas. Penelitian ini sejalan dengan penelitian yang telah dilakukan oleh Andriani, Antari, \& Rati (2014), yang memberikan sebuah hasil penelitian yaitu terdapat perbedaan yang signifikan pada aktivitas belajar IPA antara siswa yang belajar dengan menggunakan model pembelajaran Novick dan siswa yang belajar dengan menggunakan model pembelajaran konvonsional.

Berdasarkan tabel 11, tabel 12, dan tabel 13 merupakan hasil uji normalitas dan uji beda data $\mathrm{N}$-Gain tiap indikator pemahaman konsep fisika kelas eksperimen dan kelas kontrol. Selanjutnya untuk uji normalitas setiap indikator pemahaman konsep fisika, pada indikator classifying, exemplifying, inferring, dan comparing digunakan uji non-parametrik yaitu Mann Whitney $U$ Test karena data yang diperoleh pada indikator tersebut tidak normal. Sedangkan pada indikator interpreting digunakan Uji $t$ independen karena data yang diperoleh pada indikator tesebut normal. Indikator classifying, exemplifies, tidak memiliki perbedaan secara signifikan antara kedua kelas eksperimen dan kelas kontrol. Sedangkan pada indikator interpreting inferring, dan comparing terdapat perbedaan secara signifikan antara dua kelas eksperimen dan kelas kontrol. Berdasarkan diterimanya hipotesis yang dibuat oleh peneliti, hal ini disebabkan karena pada penelitian ini menggunakan pembelajaran model Novick dimana pembelajaran ini mempunyai kelebihan-kelebihan diantaranya membantu siswa untuk mengingat materi dalam jangka waktu yang lama, dapat mengembangkan kemampuan berfikir siswa menjadi berfikir ilmiah, dan menjadikan siswa aktif dalam proses pembelajaran sehingga siswa lebih termotivasi untuk belajar. Selain itu pembelajaran ini juga mendorong siswa untuk menemukan suatu konsep sendiri melalui masalah yang di berikan oleh peneliti dalam bentuk lembar kerja peserta didik (LKPD) yang berguna sebagai alat untuk membantu proses pembelajaran agar peserta didik lebih aktif dan mandiri untuk memahami dan memecahkan masalah dari percobaan yang diberikan. Selain itu LKPD juga memudahkan pendidik (guru) dalam mengajar.

Berdasarkan tabel 12 menyajikan Hasil uji effect size kelas eksperimen dan kelas kontrol sebesar 1,36 yang termasuk kategori tinggi. Hal ini menunjukkan bahwa penerapan model pembelajaran Novick efektif untuk meningkatkan pemahaman konsep fisika siswa pada materi elastisitas dan hukum hooke.

\section{PENUTUP}

Berdasarkan penelitian yang telah dilakukan terkait penerapan model pembelajaran Novick untuk meningkatkan pemahaman konsep fisika siswa SMK pada materi elastisitas dan hukum hooke dapat disimpulkan bahwa peningkatan pemahaman konsep fisika siswa SMK pada materi elastisitas dan hukum hooke dengan menerapkan model pembelajaran Novick pada kelas eksperimen mengalami peningkatan dengan kategori sedang yang ditunjukkan dengan hasil $N$-Gain sebesar 0,69 , sedangkan pada kelas kontrol memperoleh nilai $\mathrm{N}$-Gain sebesar 0,49 dengan kategori sedang. Selain itu peningkatan pemahaman konsep fisika siswa juga dianalisis dengan uji beda antara kelas eksperimen dan kontrol dengan menggunakan uji non-parametrik yaitu Mann Whitney $U$ Test dan hasil nilai $p$-value sebesar 0,000 yang artinya adalah terdapat perbedaan yang signifikan antara pemahaman konsep fisika siswa setelah diterapkan model pembelajaran Novick dengan model konvensional.

Keefektifan model pembelajaran Novick 
Keefektifan Model Pembelajaran...

terhadap peningkatan pemahaman konsep fisika siswa SMK pada materi elastisitas dan hukum hooke adalah tinggi. Hal tersebut ditunjukkan oleh hasil uji effect size sebesar 1,36 .

Berdasarkan penelitian yang telah dilakukan maka peneliti menyampaikan beberapa saran, antara lain.

Dalam meningkatkan pemahaman konsep fisika, sebaiknya pemberian masalah disajikan dengan lebih kompleks, sehingga siswa mampu menganalisis masalah dengan memikirkan berbagai macam kemungkinan jawaban dari sudut pandang yang berbeda. Model ini juga dapat diterapkan untuk mata pelajaran lainnya yang memerlukan pengetahuan konsep yang kuat seperti matematika, kimia, sedangkan untuk materi fisika selain elastisitas dan hukum hooke, model pembelajaran Novick dapat diterapkan pada materi gerak dan gaya, kalor, usaha dan energi.

Pemahaman konsep fisika siswa dapat ditingkatkan dengan lebih baik jika penerapan model pembelajaran Novick dilakukan secara terus-menerus. Sehingga pihak sekolah dapat melatih para guru untuk dapat menerapkan model pembelajaran ini, khususnya pada guru bidang sains.

Pada hasil penelitian ini, terdapat tiga indikator yang perlu ditingkatkan yaitu classifying dan exemplifies. Sehingga peneliti menyarankan untuk penelitian selanjutnyauntuk lebih memfokuskan pada peningkatan indikator classifying dan exemplifies. Hal tersebut dapat dilakukan dengan cara lebih memfokuskan pada pertanyaan-petanyaan yang dapat membangun rasa percaya diri pada siswa, dan memperbanyak soal pre-test dan post-test untuk indikator classifying dan exemplifies yang dapat menggali pengetahuan yang dimilki siswa setelah proses pembelajaran berlangsung.

\section{DAFTAR PUSTAKA}

Ardi. (2016). Penerapan Model Pembelajaran Novick untuk Meremediasi Miskonsepsi Siswa Pada Hukum Archimedes di SMP. Skripsi tidak dipublikasikan. Universitas Tanjungpura.
Ardiansyah, M \& Ali, Y.K. (2015). Penerapan Model Pembelajaran Novick untuk Meningkatkan Hasil Belajar Fisika Siswa Kelas X SMA Negeri 1 Sojol. Jurnal Pendidikan Fisika Tadulako (JFFT), 2(3), 2427.

Andriani, G.A.K.R., Antari, N.N.M., \& Rati, N.W. (2014). Pengaruh Model Pembelajaran Novick Terhadap Aktivitas Belajar IPA Siswa Kelas V. Jurnal Mimbar PGSD Universitas Pendidikan Ganesha. 2(1),1-2.

Hake, R.R. (2002). Relationship of Individual Student Normalized Learning Gains in Mechanics With Gender, High School Physics and Pretest Scores on Mathematical and Spatial Visualization. Diakses pada tanggal $10 \quad$ Mei 2019 dari https://www.researchgate.net/publication/237 457456 Relationship_of Individual_Student _Normalized_Learning_Gains_in_Mechanics with_Gender_High-

School_Physics_and_Pretest_Scores_on_M athematics_and_Spatial_Visualization

Kalsum, U. (2017). Penerapan Model Pembelajaran Novick terhadap Pemahaman Konsep Fisika Siswa Kelas XI MIPA SMA Negeri 1 Pamboang. Skripsi tidak dipublikasikan. Universitas Sulawasi Barat.

Marlina, R. (2014). Pengaruh Model Pembelajaran Kontruktivisme Tipe Novick Terhadap Kemampuan Pemahaman Konsep Relasi dan Fungsi. Skripsi tidak dipublikasikan. UIN Syarif Hidayatullah.

Rezeki, S. (2017). Meningkatkan Kemampuan Representasi Matematis Siswa Melalui Penerapan Model Pembelajaran Novick. Jurnal SAP, 1(3), 281-291.

Belia, S. (2014). Pengaruh Penerapan LKS Fisika Berbasis Masalah Padang. Skripsi tidak dipublikasikan. Universitas Negeri Padang.

Sudjana, N. (2016). Penilaian Proses Hasil Belajar Mengajar. Bandung: PT. Remaja Rosdakarya.

Sulaiman, N. (2013). Efektifitas Model Pembelajaran Novick Dalam Pembelajaran Kimia Kelas XII IA 2 SMAN 1 Donri-Donri", Jurnal Chemica, 13 (2), 67-73.

Taufiq, A., Mikarsa, H.L., dan Prianto, P.L. (2010). Pendidikan SD. Jakarta: Universitas 
Terbuka.

Trianggono, M.M. (2017). Analisis kualitas Pemahaman Konsep Dengan Kemampuan Berpikir Kreatif Siswa Pada Pemecahan Masalah Fisika. Jurnal Pendidikan Fisika dan Keilmuan (JPFK), 3(1), 1-12. 